\title{
Feasibility and practicability studies of an evaluation index system for implementation of smoke-free laws and regulations of cities in China
}

\author{
Lili Song ${ }^{1}$, Xiaowei Luo ${ }^{1}$, Jie Yang ${ }^{7}$
}

\begin{abstract}
INTRODUCTION The aim of the study is to adjust and improve the feasibility and practicability of an evaluation index system, developed for the implementation of smoke-free laws and regulations, by applying it to analyze and compare the contents and implementation of smoke-free laws and regulations in eight legislative cities in China.

METHODS In regard to indicators of the established evaluation index system, data on tobacco control/smoke-free laws and regulations and their implementation in some legislative cities in China were collected, sorted, and compared, to examine and adjust the feasibility and practicality of the indicators.

RESULTS The evaluation index system for implementation of smoke-free laws and regulations of cities in China has been adjusted to include 5 first-level indicators, including: 1) Simple, clear and executable legislation; 2) Careful planning and sufficient resources for law enforcement; 3) Participation of civil society; 4) Communication; and 5) Monitoring and evaluation of the implementation and impact of laws. There were 27 second-level indicators, including management department, scope of smoke-free places, requirements for non-smoking places etc. There were 27 third-level indicators, including construction of law enforcement, coordination network, work of coordination agencies, staffing situation etc.

CONCLUSIONS The preliminary adjusted evaluation index system for the implementation of smoke-free laws and regulations of cities in China provides a reference and standardization for evaluating effectiveness of implementation of Chinese tobacco control laws and regulations.
\end{abstract}

AFFILIATION
1 Chinese Center for Disease
Control and Prevention,
Beijing, China
CORRESPONDENCE TO
Jie Yang. Tobacco Control
Office, Chinese Center
for Disease Control and
Prevention, Beijing, China.
E-mail: bjyangjie@163.com
KEYWORDS
smoke-free regulations, law
enforcement, evaluation
index system
Received: 21 December 2020
Revised: 10 November 2021
Accepted: 24 November 2021

\section{INTRODUCTION}

Creation of a smoke-free environment through the implementation of comprehensive smoke-free legislation is considered the only way to effectively protect people from the dangers of secondhand smoke $^{1}$. Assessment of the implementation of tobacco control regulations, an important process to ensure effective implementation of smoke-free regulations, can identify existing problems and provide guidance and reference in upgrading tobacco control work. At present, there is not a well-recognized evaluation system for the implementation of China's smoke-free regulations, nor a selection standard of evaluation methods and indicators, and the monitoring and evaluation capabilities in tobacco control at city-level are still weak, resulting in that evaluation results are not comparable among cities.

In 2019, Luo et al. ${ }^{2}$ established an evaluation index system for the implementation of smoke-free laws and regulations of cities in China and assigned a weight to each indicator. The evaluation index system included 5 first-level indicators: 1) Simple, clear and executable legislation; 2) Careful planning and sufficient resources for law enforcement; 3) Participation of 
civil society; 4) Communication; and 5) Monitoring and evaluation of the implementation and impact of laws. There were 29 second-level indicators and 33 third-level indicators (Supplementary file).

This article develops a data collection table based on the established evaluation index system for the implementation of smoke-free laws and regulations of cities in China, to collect, sort and analyze the data of the legislative cities, and to analyze the content of the smoke-free laws of cities and the actual progress of smoke-free laws and regulations enforcement to improve the evaluation index system.

\section{METHODS}

\section{Selection of research cites}

From the cities that have implemented tobacco control laws and regulations in China, taking their actual work situation of tobacco control legislation, law enforcement and publicity into consideration, eight cities were selected as the research sites: Beijing, Shanghai, Shenzhen, Harbin, Hangzhou, Lanzhou, Qingdao, and Xining.

\section{Data collection and sorting}

Based on the evaluation index system determined by our previous research ${ }^{2}$, and through discussions among the research team, a data collection form was designed, 'Data Collection Form for the Implementation of Urban Smoke-Free Regulations (Trial)', hereinafter referred to as the Data Collection Form (Trial).

The Data Collection Form (Trial) was sent to the main coordinating managers of urban tobacco control work by email/WeChat. Data on urban law enforcement, publicity and education, social participation, monitoring and evaluation etc., were collected, including related documents/notifications, law enforcement data, reports, etc. At the same time, other information was collected through the Internet, including the text of urban smoke-free regulations, urban population, and economic level, which mainly came from Baidu Encyclopedia, the official website of the City People's Congress, the official website of the Bureau of Statistics etc. Part of the data comes from the report of the Chinese Center for Disease Control and Prevention.

After completion of the data collection, the data were organized and summarized one by one according to the evaluation index system. The problems found during the sorting and analysis process were recorded and discussed by the research team, and finally reasonable solutions were agreed upon.

According to the established evaluation index system, the status of smoke-free laws and regulations and their implementation in various cities were analyzed and the index system was adjusted.

\section{Statistical analysis}

We used Excel 2016 to establish a database for data collection results on the implementation of smokefree laws and regulations.

\section{Quality control}

The Data Collection Form (Trial) was finalized after experts' consultation and revision and after sending out the Data Collection Form (Trial) by email, ensuring that all city contacts received the email by phone or WeChat. After data collection, the data were collated by two professionals at the same time. If there was any inconsistency, it was resolved through discussions by the research team.

\section{RESULTS}

\section{Contents of smoke-free laws and regulations}

Regulatory level, scope of application, and administrative departments

The level of legislation for smoke-free regulations in the research cities was local. From the perspective of the scope of application, except for the Harbin City Regulations on Preventing the Harm of Secondhand Smoke Tobacco Smoke ${ }^{3}$, which covers the central city, the rest covered the whole cities. From the perspective of administrative departments, the main management departments for smoke-free regulations in seven cities are the Patriotic Health Campaign Committee, the Health Promotion Committee, and the Smoking Control Leading Group and other institutions, while Hangzhou is the health administrative department.

\section{Enforcement procedures and fines}

From the perspective of enforcement procedures and fines, each city varies. The smoke-free laws of Shanghai and Lanzhou stipulate that both individuals and venues can be fined directly, while Beijing, Shenzhen, Harbin, Qingdao, and Xining, stipulate that 
individuals can be fined directly, whereas venues need to be warned and ordered to make rectifications within a time limit. Those who fail to make rectifications shall be fined. Hangzhou City stipulates that both individuals and venues need to be warned first, and those who refuse to make rectifications shall be fined (Table 1).

The requirements of smoke-free laws and regulations on non-smoking venues

Judging from the requirements of the laws and regulations on non-smoking venues, all eight cities have imposed the necessary duties and statutory obligations on the managers or operators of the venues. However, from the perspective of specific requirements, there are differences: although all cities have requirements for 'set up standard no-smoking signs' and 'dissuade illegal smokers', the other items are not required. Only the 'Beijing Regulations on Smoking Control' made the requirement of 'carry out tobacco control inspections and keep records' on nonsmoking venues (Table 2 ).

\section{Careful planning and sufficient resources for law and regulations enforcement}

Personnel and law enforcement funding input in cities Lanzhou and Harbin have full-time staff responsible for tobacco control coordination. Qingdao City has the highest proportion of law enforcement personnel directly involved in tobacco control law enforcement (24.54\%), and Hangzhou City has the lowest $(12.28 \%)$. The results show that none of the eight city law enforcement agencies has set up separate funds for tobacco control law enforcement, so it is impossible to calculate the investment in tobacco control law enforcement (Table 3).

Documents related to the implementation of laws and regulations

All cities have issued plans or programs on tobacco control law enforcement in the form of documents, but the names and quality of the documents are different. At the beginning of each year, Beijing, Shanghai, Lanzhou etc. issued the tobacco control law enforcement work-plan for that year to clarify the key tasks of each law enforcement unit that year. However, from the perspective of law enforcement guidelines or detailed rules, only Shenzhen and Lanzhou currently have corresponding documents. Hangzhou City has issued guidance on the discretion of the punishment procedure. From the data collected so far, no other cities have formulated such documents.

\section{Law enforcement assessment system}

Judging from the data collected so far, except for Qingdao City, there are corresponding supervisions

Table 1. Basic situation of smoke-free laws and regulations in eight cities

\begin{tabular}{|c|c|c|c|c|}
\hline \multirow[t]{2}{*}{ City } & \multirow[t]{2}{*}{ Scope of application } & \multirow[t]{2}{*}{ Administrative departments } & \multicolumn{2}{|c|}{ Fine amount (RMB) } \\
\hline & & & Individual & Place \\
\hline Beijing & The whole city & Patriotic Health Campaign Committee (Office) & $50 ; 200$ & $2000-10000$ \\
\hline Shanghai & The whole city & Health Promotion Committee (Office) & $50-200$ & $\begin{array}{l}\text { 2000-10000 } \\
10000-30000 \\
\text { (The circumstances are serious) }\end{array}$ \\
\hline Shenzhen & The whole city & $\begin{array}{l}\text { Joint Conference on Tobacco Control Work } \\
\text { (The office is located in the Municipal Health } \\
\text { Commission) }\end{array}$ & $50 ; 200 ; 500$ & $10000-30000$ \\
\hline Harbin & The central city & $\begin{array}{l}\text { Tobacco Control Regulations Leading Group } \\
\text { Work (Office) }\end{array}$ & 200 & $\begin{array}{l}\text { 2000-10000; } 1000-30000 \\
\text { (The circumstances are serious) }\end{array}$ \\
\hline Hangzhou & The whole city & Health Administration Department & 50 & $500-2000$ \\
\hline Lanzhou & The whole city & $\begin{array}{l}\text { Tobacco Control Leading Group (The office is } \\
\text { located in the Municipal Health Commission) }\end{array}$ & $50 ; 200$ & $2000-10000$ \\
\hline Qingdao & The whole city & Patriotic Health Campaign Committee (Office) & 200 & $\begin{array}{l}\text { 1000-10000; } 10000-30000 \\
\text { (The circumstances are serious) }\end{array}$ \\
\hline Xining & The whole city & Patriotic Health Campaign Committee (Office) & $50 ; 200$ & $1000-30000$ \\
\hline
\end{tabular}


Table 2. The requirements of the smoke-free laws and regulations for non-smoking places in eight cities

\begin{tabular}{|c|c|c|c|c|c|c|c|c|}
\hline City & $\begin{array}{l}\text { No smoking } \\
\text { management } \\
\text { system }\end{array}$ & $\begin{array}{c}\text { Set up } \\
\text { standard } \\
\text { no-smoking } \\
\text { signs }\end{array}$ & $\begin{array}{l}\text { No smoking } \\
\text { utensils }\end{array}$ & $\begin{array}{l}\text { No tobacco } \\
\text { advertisement }\end{array}$ & $\begin{array}{l}\text { Carry out } \\
\text { tobacco } \\
\text { control } \\
\text { inspections } \\
\text { and keep } \\
\text { records }\end{array}$ & $\begin{array}{l}\text { Discourage } \\
\text { illegal } \\
\text { smokers }\end{array}$ & $\begin{array}{l}\text { Set up smoke } \\
\text { control } \\
\text { inspectors or } \\
\text { supervisors }\end{array}$ & $\begin{array}{l}\text { Publicity and } \\
\text { education }\end{array}$ \\
\hline Beijing & $\checkmark$ & $\sqrt{ }$ & $\sqrt{ }$ & $\sqrt{ }$ & $\sqrt{ }$ & $\checkmark$ & & $\sqrt{ }$ \\
\hline Shanghai & & $\sqrt{ }$ & $\checkmark$ & & & $\sqrt{ }$ & $\sqrt{ }$ & $\checkmark$ \\
\hline Shenzhen & $\checkmark$ & $\checkmark$ & $\checkmark$ & $\sqrt{ }$ & & $\checkmark$ & $\checkmark$ & $\checkmark$ \\
\hline Harbin & $\sqrt{ }$ & $\checkmark$ & $\checkmark$ & & & $\sqrt{ }$ & $\checkmark$ & \\
\hline Hangzhou & $\checkmark$ & $\sqrt{ }$ & $\checkmark$ & $\checkmark$ & & $\checkmark$ & & \\
\hline Lanzhou & $\checkmark$ & $\sqrt{ }$ & $\checkmark$ & $\sqrt{ }$ & & $\checkmark$ & $\checkmark$ & $\checkmark$ \\
\hline Qingdao & $\sqrt{ }$ & $\sqrt{ }$ & $\sqrt{ }$ & $\checkmark$ & & $\sqrt{ }$ & & \\
\hline Xining & $\sqrt{ }$ & $\checkmark$ & $\checkmark$ & & & $\sqrt{ }$ & $\checkmark$ & \\
\hline
\end{tabular}

$\sqrt{ }$ Means there is such a requirement.

Table 3. Status of staffing related to tobacco control in each city

\begin{tabular}{|c|c|c|c|c|c|}
\hline \multirow[t]{2}{*}{ City } & \multicolumn{2}{|c|}{ Coordinating agency staff * } & \multicolumn{3}{|c|}{ Law enforcement officers * } \\
\hline & Full-time & Part-time & $\begin{array}{l}\text { Total number of } \\
\text { departmental law } \\
\text { enforcement officers }\end{array}$ & $\begin{array}{l}\text { Number of people } \\
\text { directly involved in } \\
\text { tobacco control law } \\
\text { enforcement }\end{array}$ & $\begin{array}{l}\text { Proportion of persons } \\
\text { directly involved in } \\
\text { tobacco control law } \\
\text { enforcement }(\%)\end{array}$ \\
\hline Beijing & 0 & 10 & 1600 & 300 & 18.75 \\
\hline Shanghai & 0 & 36 & 11207 & 2129 & 19.00 \\
\hline Shenzhen & 0 & 15 & 5745 & 1000 & 17.41 \\
\hline Harbin & 5 & 30 & 1733 & 329 & 18.98 \\
\hline Hangzhou & 0 & 0 & 57 & 7 & 12.28 \\
\hline Lanzhou & 3 & 8 & 8780 & 2193 & 24.98 \\
\hline Qingdao & 0 & 3 & 2991 & 734 & 24.54 \\
\hline Xining & 0 & 19 & 600 & 250 & 24.00 \\
\hline
\end{tabular}

* Both include cities and counties (districts) and all law enforcement agencies. Some data are estimated based on the number of jurisdictions; the number of law enforcement officers in Xining City includes only the Food and Drug Administration.

and inspections. However, the systems implemented in various cities are inconsistent. Beijing, Harbin, and Lanzhou, have formulated regular assessment systems. The assessment content involves the implementation of responsibilities of law enforcement agencies, the construction of tobacco control law enforcement work systems, and the construction of smoke-free environments in venues. The assessment methods include documents review, reporting meetings, onsite inspections, etc. The supervision and inspections conducted in Shanghai, Shenzhen, Hangzhou, and Xining, are only inspections of non-smoking venues and do not involve the implementation of the duties of law enforcement agencies or the government.

\section{Law enforcement tools}

Except Hangzhou and Lanzhou with lack of invoice and confiscated accounts, other cities are equipped with corresponding law enforcement tools (Table 4).

Non-smoking sign posting rate and qualification rate Judging from the current data collected, only Beijing, Shanghai, and Shenzhen, have carried out corresponding survey work, while other cities have not 
carried out relevant work. Judging from the results, the non-smoking signs are all used in the three cities, but Shanghai has not adopted qualification rate of the non-smoking signs.

By the end of our survey, the results of Shenzhen in 2018 were not released, so we only compare the results of 2016 and 2017 . The posting rates in the three cities all exceeded $80 \%$. The rate of nonsmoking signs in Shanghai was the highest, exceeding 95\% in both 2016 and 2017. In 2017, the qualification rate of non-smoking signs reached $93.3 \%$ in Beijing and $70.3 \%$ in Shenzhen (Table 5).

\section{Law enforcement actions and fines}

All cities have carried out tobacco control law enforcement activities. Beijing, Shenzhen, and Shanghai, have a relatively high number of sites inspected, with more than 50000 sites each year. In particular, Shanghai had more than 150000 sites in 2016 and more than 200000 sites in 2017 and 2018. In contrast, Harbin had much fewer conducted

Table 4. Situation of law enforcement tools in eight cities

\begin{tabular}{|c|c|c|c|}
\hline City & $\begin{array}{l}\text { Tobacco control } \\
\text { enforcement } \\
\text { invoice or } \\
\text { receipt }\end{array}$ & $\begin{array}{c}\text { Tobacco control } \\
\text { enforcement } \\
\text { penalty account }\end{array}$ & $\begin{array}{l}\text { Law } \\
\text { enforcement } \\
\text { equipment* }\end{array}$ \\
\hline Beijing & $\sqrt{ }$ & $\checkmark$ & $\sqrt{ }$ \\
\hline Shanghai & $\sqrt{ }$ & $\sqrt{ }$ & $\sqrt{ }$ \\
\hline Shenzhen & $\sqrt{ }$ & $\sqrt{ }$ & $\sqrt{ }$ \\
\hline Harbin & $\sqrt{ }$ & $\sqrt{ }$ & $\sqrt{ }$ \\
\hline Hangzhou & & & $\sqrt{ }$ \\
\hline Lanzhou & & & $\sqrt{ }$ \\
\hline Qingdao & $\sqrt{ }$ & $\sqrt{ }$ & $\sqrt{ }$ \\
\hline Xining & $\sqrt{ }$ & $\sqrt{ }$ & $\sqrt{ }$ \\
\hline
\end{tabular}

inspections, less than 7000 establishments in 20162018. From the point of view of punishments on establishments, Shenzhen had the largest number of warnings and orders for rectification every year, more than 5000 establishments. However, Shenzhen imposes fewer fines and fines on establishments, with less than 10 establishments every year; in 2017 and 2018, Shanghai had 1133 and 1671 establishments fined and penalized, the highest among the eight cities. From the perspective of the fines imposed on individuals, except Shenzhen and Beijing, other cities rarely impose fines on individuals; Shenzhen imposes fines on more than 20000 individuals who smoke illegally each year, which is the highest among the eight cities and is also much higher than Beijing's annual fines on over 3000 individuals (Supplementary file).

\section{Communication}

Judging from the data collected so far, Shanghai has invested the most in publicity, with an annual investment of more than 3 million RMB (1000 Chinese Renminbi about US\$160). Large-scale publicity activities have been held in Shanghai, Shenzhen, Lanzhou, and Xining, more often. From the perspective of communication methods, various cities have adopted various approaches for tobacco control communication. Beijing, Shanghai, and Shenzhen, conduct annual surveys to monitor the public's awareness of tobacco hazards. However, the data collected so far is limited. In 2017, the awareness rates of tobacco hazards in Shanghai and Shenzhen were $69.6 \%$ and $68.0 \%$. As for the core knowledge of smoke-free regulations, the indicators adopted by cities are inconsistent, including: awareness rate of smoke-free regulations, awareness rate of nonsmoking venues, awareness rate of fines, awareness rate of complaint hotline, etc. The indicators adopted by each city are one or more of the above.

Table 5. Posting rate and qualification rate of non-smoking signs

\begin{tabular}{|c|c|c|c|c|c|c|}
\hline \multirow[t]{2}{*}{ City } & \multicolumn{3}{|c|}{ Non-smoking sign posting rate or setting rate (\%) } & \multicolumn{3}{|c|}{ Qualification rate of non-smoking signs (\%) } \\
\hline & 2016 & 2017 & 2018 & 2016 & 2017 & 2018 \\
\hline Beijing & 82.0 & 94.7 & 96.4 & + & 93.3 & + \\
\hline Shanghai & 95.2 & 98.0 & 97.7 & + & + & + \\
\hline Shenzhen & 81.5 & 86.8 & + & 59.1 & 70.3 & + \\
\hline
\end{tabular}

+ Indicators are not adopted or the survey in the data collection phase is not completed. 


\section{Monitoring and evaluation of the implementation and impact of laws}

Judging from the data collected so far, from 2016 to 2018, only Beijing, Shanghai, and Shenzhen, have formed a regular monitoring and evaluation mechanism, which monitors and evaluates the implementation of laws and regulations every year, and releases the evaluation results to the public. From the perspective of the evaluation of the implementation of laws and regulations, only Beijing, Shanghai, and Shenzhen, have conducted surveys on illegal smoking rates, tobacco smoke concentrations in non-smoking venues, and support rates for smokefree laws. It is only these three cities that have conducted by themselves 'The survey on the smoking prevalence of adults over 15 years old' in 2016-2018, while the survey conducted in 2013 in Harbin, Hangzhou, Lanzhou, and Qingdao, was conducted by the Tobacco Control Office of the Chinese Center for Disease Control and Prevention. From the perspective of the health effect evaluation of the implementation of smoke-free regulations, only Beijing conducted one, but the relevant results have not been published. The remaining seven cities have not carried out or reported relevant evaluations. However, it is good to know Beijing, Shanghai, Shenzhen, and Harbin, have established surveillance systems for the incidence or death of tobacco-related diseases.

\section{Adjustment of the evaluation index system}

On the basis of collating and analyzing the data of each city, the following adjustments were made to the indicator system:

- Exclude '1.2 scope of application', '1.10 advocacy clause', '2.1.4 investments in law enforcement per 10000 people', '2.2.4 pass rate of non-smoking labels', '2.5.1 number of inspection sites per 10000 people', '2.5.2 The number of warnings and orders for rectification per 10000 people', '2.5.5 Amounts of fines per 10000 people';

- Improve the scores of the following indicators in the evaluation index system '1.6 Requirements for NonSmoking Places', 'Establish a smoking management system', 'Set up standard no-smoking signs', 'No smoking utensils and no tobacco advertisements', 'Dissuade illegal smokers' and 'set up tobacco control inspectors or supervisors';

- The evaluation indicators of '2.1.3 Staffing
Situation' only includes the staff of the tobacco control coordination agency, excluding the law enforcement personnel;

- The evaluation indicators of '4.3 Communication Methods' should highlight the role of traditional media. It is recommended to score in accordance with 'traditional media', 'new media', and 'other methods', and increase the score of 'traditional media', or continue to explore more objectively quantitative indicators for evaluation;

- The scores of the World No Tobacco Day communication activities are highlighted in the evaluation criteria of '4.4 Publicity Activities';

- '4.5.1 Awareness rate of core knowledge of smokefree laws and regulations of the public' is replaced with '4.5.1 Awareness rate of smoke-free laws and regulations';

- '4.5.2 Awareness rate of public tobacco hazards' is replaced with '4.5.2 Awareness rate of stroke caused by smoking'.

See Supplementary file Appendix 3 for the adjusted evaluation index system for the implementation of smoke-free regulations.

\section{DISCUSSION}

\section{Indicators of the contents of laws and regulations}

At present, there are no national tobacco control regulations in China, and there are also large differences between urban regulations, such as the scope of smoke-free venues and fines. This difference will have an impact on the efficiency of the implementation of the regulations, so it is necessary to include indicators about the contents of the regulations in the evaluation index system.

The management requirements of no-smoking areas are the duties and statutory obligations that must be fulfilled by the operators and managers of non-smoking areas, and are of great significance to the creation of smoke-free environments. At present, all cities are advocating 'Four Availables, No ash tray or tobacco ads, and Dissuasion' but the requirements of each city are still different. In order to play an exemplary role, the evaluation clauses in '1.6 Requirements for No Smoking Places' have been adjusted in proportion.

According to the evaluation criteria, the two indicators of ' 1.8 law enforcement procedures' 
and ' 1.9 fines' require experts to review the text of the regulations, so that there is a certain degree of subjectivity in the evaluation criteria. The fines (enforcement procedures and fines) in smoke-free regulations are the most important provisions that reflect the enforcement of regulations and enhance the deterrent effect of regulations. In the study of Ravara et al. ${ }^{4}$, the main reason for taxi drivers to comply with smoke-free regulations is the mandatory fines of smoke-free regulations. Whether or not to be able to effectively punish violations is a prerequisite for deterrent regulations. The results of interviews with relevant personnel also show that the cancellation of warnings (for individuals) and the cancellation of orders for rectification (for venues) will increase the efficiency of law enforcement and greatly increase the deterrent effect of smoke-free regulations.

Therefore, experts should evaluate the " 1.8 law enforcement procedures' based on whether the punishment procedures are simple and can improve the efficiency of law enforcement. Too high or too low fines will affect the efficiency of law enforcement and the deterrent effect of regulations. Because the appropriateness of the fines is affected by various factors such as the city's economic level, experts should evaluate the amount of ' 1.9 fines' based on the experts' practical experience, to determine whether the amount of punishment is appropriate and whether it is conducive to improving the efficiency of law enforcement.

\section{Indicators of law enforcement}

Because the multi-sector law enforcement model involves many units, it makes it difficult to estimate the number of law enforcement personnel. Some cities have not given the status of law enforcement personnel, so the data cannot be used for evaluation. The results of the study show that all cities have not increased the number of grassroots law enforcement personnel after the smoke-free legislation's enactment, only adding the part of tobacco control law enforcement to the comprehensive law enforcement content of each law enforcement unit. The number of law enforcement personnel still depends on the original configuration. Therefore, the deployment of law enforcement personnel is not suitable for inclusion in the evaluation system of the implementation of smoke-free regulations. The staff of the coordinating agency is an important foundation for the smooth implementation of the city's smoke-free regulations and should be used as an evaluation indicator. In summary, adjustments should be made to ' 2.1 .3 Staffing Situation'.

Analysis of the data shows that the eight cities cannot clearly provide funding for tobacco control law enforcement. From the interviews, it was found that the law enforcement departments included tobacco control law enforcement in the work of comprehensive law enforcement, and the funding input was only a part of the comprehensive law enforcement funds. The tobacco control law enforcement funds were not established separately, so the relevant information could not be clearly provided. Therefore, the setting of this indicator does not conform to the actual situation of the city, and the indicator of '2.1.4 investment in law enforcement funds per 10000 people' should be eliminated.

According to the indicator system and evaluation standards, the two indicators of '2.1.5 Law Enforcement Documents' and '2.1.6 Law Enforcement Assessment System' require experts to evaluate based on practical experience, which is subjective. According to WHO's 'Making cities smoke-free and Research Report on China's Urban Tobacco Control Law Enforcement' ${ }^{4,5}$, the law enforcement documents should include law enforcement plans or programs, law enforcement guidelines or rules, and the content should cover the following parts: general introduction of smoke-free regulations; law enforcement coordination mechanism and organization settings; overall law enforcement strategy; complaint line management and complaint reporting feedback mechanism; law enforcement preparation; and monitoring and evaluation of law enforcement.

With regard to '2.2.3 Non-smoking sign posting rate or setting rate' and '2.2.4 Non-smoking sign passing rate', in Portugal it is required to post signs in service venues and taxis, and relevant research shows that these venues have higher rates of compliance with smoke-free regulations. In contrast, in some restaurants and educational institutions in India, where non-smoking signs are not posted, the compliance rate in these places is also low, indicating that the posting of non-smoking signs is an important part of the environmental construction of non-smoking venues $^{6-8}$. Data analysis shows that some cities do not 
use the non-smoking sign qualification rate indicators, and the interview results show that most non-smoking signs in non-smoking venues are uniformly printed and issued by law enforcement units. Therefore, only the posting rate or setting rate of non-smoking signs can be used to evaluate the situation of non-smoking signs in venues. The deletion of the indicator 'Nonsmoking sign passing rate' is suggested.

The law enforcement action and punishment result indicators are the process indicators to measure the output of the law enforcement departments of tobacco control, but there are five indicators in the current indicator system for evaluation, which is slightly cumbersome and not easy to implement the comprehensive evaluation. In order to make the indicator system more convenient, the indicators were deleted. Since the amounts of fines stipulated by the smoke-free laws of various cities varies greatly, in order to make the results more comparable, the number of individual penalty cases per 10000 people is used as an evaluation indicator.

\section{Indicators of communication and education}

The results of data collation and analysis show that there are differences among cities in terms of communication methods. When sorting and analyzing the data of each city, it is found that the cost and the effects of different communication methods are inconsistent, so according to the current evaluation standards (the same scores for various communication methods) are not suitable and need to be adjusted. According to "China Tobacco Control', the current communication channels for tobacco control in China can be divided into two categories: traditional media and new media, and the influence of traditional media is still unmatched, so it should account for a large proportion of the score. According to the data of the cities, other methods such as posters are also used, and they also need to account for a certain proportion of the index score.

In regard to ' 4.5 Communication Effect', under this second-level indicator, there are two third-level indicators: "4.5.1 Public knowledge rate of core knowledge of smoke-free regulations' and '4.5.2 Public knowledge rate of tobacco harm knowledge'. The results of the study show that because the current surveys in cities are conducted independently, the indicators used are inconsistent, which makes horizontal evaluation impossible. Therefore, for the evaluation of publicity effects, a specific indicator should be selected for evaluation. According to previous studies ${ }^{10}$, the awareness rate of smoke-free regulations is a commonly used indicator for smokefree regulations. As for the awareness rate of tobacco hazards, higher awareness rate (lung cancer) or lower (sexual dysfunction) is not suitable as an effect indicator of horizontal comparison. It is recommended to choose the awareness rate of stroke caused by smoking as an indicator, which can better reflect the communication effect.

\section{Limitations}

The indicator system is a bit cumbersome, which may hinder the promotion and application of the next step, so it needs to be further adjusted in practice.

\section{CONCLUSIONS}

This study initially improves the indicator system by omitting the least effective second-level and thirdlevel indicators from the aspects of feasibility and practicability, and proposes a more scientific and practical one. It serves as a base for the next step to establish a more feasible and practical evaluation index system for the implementation of smoke-free laws and regulations. Besides, it also provides a scientific basis for tobacco control legislation, law enforcement, and amendments in terms of what are essentials in practice. However, the indicator system still needs to be examined in practice and further improved. It is recommended to continue research, through practice, to further improve the comprehensive evaluation index system, and to establish a more effective data collection method or approach, and finally establish a comprehensive, scientific and simple evaluation system.

\section{REFERENCES}

1. Yang J. New developments and new requirements of smoke-free environmental legislation. Article in Chinese. Health Education and Health Promotion. 2019;14:192-212. doi:10.16117/j.cnki.31-1974/r.201903002

2. Luo X, Xiong J, Yang J. Research on the evaluation index system for the implementation of smoke-free regulations in cities in China. Article in Chinese. Capital Journal of Public Health. 2019;13(3):146-150. Accessed November 10, 2021. https://d.wanfangdata.com.cn/periodical/ChlQZXJpb2Rp Y2FsQ0hJTmV3UzIwMjExMjMwEg9zZGdnd3MyMD 
E5MDMwMTEaCHA1cG1ycmt

3. Harbin Municipal People's Government. Harbin City Regulations on Preventing the Harm of Second-hand Tobacco Smoke. In Chinese. Harbin Municipal People's Government; 2011. Accessed May 6, 2021. http://www. harbin.gov.cn/art/2011/9/5/art_222_180.html

4. Yang J. Research Report on the Enforcement of Tobacco Control in Chinese Cities. Book in Chinese. China Democracy Legal System Press; 2015.

5. World Health Organization - Regional Office for the Western Pacific. Making your city smoke free: workshop guide. World Health Organization - Regional Office for the Western Pacific; 2013. Accessed November 10, 2021. https://iris.wpro.who.int/bitstream/ handle/10665.1/7825/9789290616115_eng.pdf

6. Ravara SB, Castelo-Branc M, Aguiar P, Calheiros JM. Compliance and enforcement of a partial smoking ban in Lisbon taxis: an exploratory cross-sectional study. BMC Public Health. 2013;13:134. doi:10.1186/1471-2458-13-134

7. Kaur P, Thomas DR, Govindasamy E, Murhekar MV. Monitoring smoke-free laws in restaurants and educational institutions in Chennai, India. Natl Med J India. 2014;27(2):76-78. Accessed November 10, 2021. https://pubmed.ncbi.nlm.nih.gov/25471758/

8. Reis MF, Namorado S, Aguiar P, et al. Patterns of adherence to and compliance with the Portuguese smokefree law in the leisure-hospitality sector. PLoS One. 2014;9(7):e102421. doi:10.1371/journal.pone.0102421

9. Yang G. Tobacco control in China. Book in Chinese. China Union Medical University Press; 2018.

10. Central Broadcasting Network. Tobacco Free Shanghai joined hands to build the '2018 State of Shanghai Public Places Tobacco Control' white paper released. In Chinese. 2019. Accessed December 1, 2020. http://www.cnr.cn/ shanghai/tt/20190301/t20190301_524527064.shtml
CONFLICTS OF INTEREST

The authors have completed and submitted the ICMJE Form for Disclosure of Potential Conflicts of Interest and none was reported.

FUNDING

The study was funded by the project Writing and Promotion of the Regulations of the People's Republic of China on Tobacco Control in Public Places (2014-40-R-009), from the Chinese Center for Disease Control and Prevention.

ETHICAL APPROVAL AND INFORMED CONSENT

Ethical approval and informed consent were not required for this research.

DATA AVAILABILITY

The data supporting this research can be found in the Supplementary file.

PROVENANCE AND PEER REVIEW

Not commissioned; externally peer reviewed. 